\title{
Dúvidas de um biógrafo brasileiro de Marx
}

\author{
Carta de Angelo Segrillo
}

Resumo: Nessa carta, o autor, biógrafo de Marx, discute algumas dúvidas que surgiram durante a pesquisa sobre a vida do filósofo alemão. Trata-se de alguns pontos de interseção entre a vida de Marx e sua teoria, sobre os quais não foi encontrada explicação adequada, nem nas fontes primárias disponíveis nem nos trabalhos dos biógrafos anteriores. Mais exatamente, é abordado o tema da alienação e como ela se originou, a posição de Marx sobre o debate da "revolução permanente" e sobre a possibilidade de uma revolução na Rússia nas últimas décadas do século XIX.

Palavras-chave: Marx; Alienação; Revolução permanente; Revolução russa.

${ }^{1}$ Angelo Segrillo é Professor Associado do departamento de História da Universidade de São Paulo. E-mail: angelosegrillo@usp.br 
São Paulo, 5 de maio de 2018.

\section{Prezado Karl Marx,}

Escrevi e publiquei no ano do bicentenário de seu nascimento uma biografia sobre sua vida: Karl Marx: uma biografia dialética (Segrillo, 2018). Ela constitui, na verdade, a primeira biografia stricto sensu (baseada em fontes primárias) escrita por um historiador brasileiro (e latino-americano em geral) sobre você. Realmente foi um trabalho árduo terminá-la, pois há vários episódios obscuros em sua vida. Aliás, eu queria aproveitar a oportunidade deste canal de comunicação oferecido pelos Cadernos Cemarx para tirar algumas dúvidas que me ficaram ao fim da empreitada. São alguns pontos de interseção entre sua vida e sua teoria sobre os quais não encontrei explicação adequada nem nas fontes primárias disponíveis nem nos trabalhos dos biógrafos anteriores. $\mathrm{Na}$ verdade, alguns deles provavelmente nem têm uma "resposta certa", pois talvez sejam dúvidas até para você mesmo. De qualquer jeito, aqui vão elas. Agradeço qualquer feedback que possa dar.

O primeiro ponto se refere a um conceito fundamental que utiliza: a alienação. Ele ocupou o papel de fio condutor no amadurecimento de sua obra. Foi também utilizado para explicar, em grande medida, a exploração do homem pelo homem nas sociedades de classe. Assim, uma questão, cuja resposta não consegui encontrar claramente em seus escritos, se impõe: de onde vem a alienação?

Uma primeira análise, superficial, poderia fornecer uma resposta aparentemente lógica: a alienação provém da propriedade privada. Afinal, isso encaixaria com aquele modelo tradicional do marxismo ortodoxo da sociedade humana saindo de um comunismo primitivo original (onde não haveria propriedade privada, classes, Estado ou exploração) e, após o big bang do aparecimento da propriedade privada, passando por escravismo, feudalismo e capitalismo (onde a exploração 
de classe e alienação reinariam) para depois haver uma superação desses problemas em um futuro estágio de comunismo científico.

Entretanto, não é isso que você afirmou. No primeiro dos seus Manuscritos Econômico-Filosóficos de 1844, você peremptoriamente diz que não é a propriedade privada que causa a alienação e sim, ao contrário, é a alienação que leva à propriedade privada.

É verdade que extraímos o conceito de trabalho alienado (vida alienada) da economia política, partindo de uma análise do movimento da propriedade privada. A análise deste conceito, porém, mostra que embora a propriedade privada pareça ser a base e causa do trabalho alienado, é antes uma consequência dele, tal e qual os deuses não são fundamentalmente a causa, mas o produto de confusões da razão humana. Numa etapa posterior, entretanto, há uma influência recíproca. Só na etapa final da evolução da propriedade privada é revelado o seu segredo, ou seja, que é, de um lado, o produto do trabalho alienado, e do outro, o meio pelo qual o trabalho é alienado, a realização dessa alienação. (MEW, v. 40, p. 520)

Assim, para você, originalmente a propriedade privada é uma consequência, não a causa, da alienação. Mas de onde vem a alienação, então, se não é da propriedade privada? Como um Sherlock Holmes, fui seguindo o rastro da origem histórica desses fenômenos em seus escritos e devo confessar que, às vezes me senti tentando responder àquela pergunta do que veio primeiro "o ovo ou a galinha?" até atingir um anticlímax.

Você perseguiu essa questão continuando assim o primeiro manuscrito.

Como descobrimos o conceito de propriedade privada por uma análise do conceito de trabalho alienado, com o auxílio desses dois fatores também podemos deduzir todas as categorias da economia política, e em cada uma, isto é, comércio, competição, capital, dinheiro, descobriremos só uma expressão particular e ampliada desses elementos fundamentais. Sem embargo, 
antes de considerar essa estrutura, tentemos solucionar dois problemas: (1) Determinar a natureza geral da propriedade privada como resultou do trabalho alienado, em sua relação com a propriedade humana e social genuína. (2) Tomamos como fato e analisamos a alienação do trabalho. Como sucede, podemos indagar, que o homem aliene seu trabalho? Como essa alienação se alicerça na natureza da evolução humana? Já fizemos muito para resolver o problema, visto termos transformado a questão referente à origem da propriedade privada em uma questão acerca da relação entre trabalho alienado e o processo de evolução da humanidade. Pois, ao falar de propriedade privada, acredita-se estar lidando com algo extrínseco à espécie humana. Mas, ao falar de trabalho, lida-se diretamente com a própria espécie humana. Esta nova formulação do problema já encerra sua solução. (MEW, v. 40, p. 521-522)

Infelizmente, quando você anunciou acima que investigaria o mistério de como o primum mobile da alienação (trabalho alienado) se originou, dali a algumas linhas o primeiro manuscrito termina interrompido e sem continuação. Nesse ponto ficamos em suspenso com o mistério de como se origina a alienação na evolução humana já que aquela parte dos Manuscritos Econômico-Filosóficos de 1844 quedouse incompleta durante sua vida.

Felizmente, em seu livro A Ideologia Alemã (escrito conjuntamente com Engels em 1846, mas só publicado postumamente), você retomou parcialmente esse tema (mas não o arrematou). Ali você afirmou que a divisão do trabalho gera a propriedade privada ao mesmo tempo em que a divisão do trabalho é o primeiro exemplo de alienação (trabalho alienado):

Com a divisão do trabalho, na qual estão implícitas todas essas contradições, e que, por sua vez, é baseada na divisão natural de trabalho na família e na separação da sociedade em famílias individuais opostas umas às outras, está dada simultaneamente a distribuição, na verdade a distribuição desigual, quantitativa e qualitativa, do trabalho e seus produtos, ou seja, a propriedade, cujo núcleo, ou primeira forma está representado na família em que a mulher e as crianças são escravos do marido. Essa 
escravidão latente na família, apesar de ainda muito rústica, é a primeira propriedade. Entretanto, mesmo neste estágio inicial, ela corresponde perfeitamente à definição dos economistas modernos que a chamam de poder de dispor da força de trabalho dos outros. A divisão do trabalho e a propriedade privada são, além disso, expressões idênticas: a mesma coisa é afirmada em uma em relação à atividade e na outra em relação ao produto da atividade. Além disso, a divisão do trabalho implica na contradição entre os interesses das pessoas ou famílias individuais e o interesse comunal de todos os indivíduos em sociedade. Realmente, esse interesse comunal não existe na imaginação, ou como "interesse geral", mas, antes de tudo, na realidade, como a interdependência mútua dos indivíduos entre os quais o trabalho é dividido [...] Finalmente, a divisão do trabalho nos oferece o primeiro exemplo de como, quando existe uma clivagem entre o interesse comum e o particular e quando, portanto, a atividade não é voluntária, mas naturalmente, dividida, os próprios feitos do homem se tornam um poder estranho, oposto a ele e que o escraviza em vez de ser controlado por ele" (MEW, v. 3, p. 32-33; negritos meus).

Seguindo a trilha, vemos que a divisão do trabalho (o primeiro exemplo de alienação ou trabalho alienado) está também na origem da propriedade privada. Mas o que, então, levou à divisão do trabalho na história? Aqui, Marx, por mais que eu procurasse em A Ideologia Alemã, vi apenas algumas indicações muito gerais, mais do desenvolvimento desse fenômeno que de sua origem.

[...] a consciência dos homens da necessidade de se associar com os indivíduos em volta é o começo da consciência que vivem em sociedade. Este começo é tão animal quanto a própria vida social naquele momento. É apenas um sentimento de manada e os homens se diferenciam dos carneiros apenas pelo fato de que sua consciência substitui o instinto, ou que seu instinto se torna mais consciente. Essa consciência tribal ou "caprina" recebe um ulterior desenvolvimento e expansão através do crescimento da produtividade, multiplicação das necessidades e (o que é fundamental para ambos os fatores) aumento da população. 
Com isso se desenvolve a divisão do trabalho que originalmente nada mais era que a divisão do trabalho no ato sexual, depois se torna a divisão do trabalho que se desenvolve espontaneamente ou "naturalmente" em virtude das predisposições naturais (e.g., força física), necessidades, acidentes etc., etc. A divisão do trabalho só se constitui verdadeiramente como tal quando aparece a divisão entre trabalho mental e manual. Desse momento em diante, a consciência pode se convencer de que é algo mais que a consciência de práticas existentes [...] Os vários estágios de desenvolvimento da divisão do trabalho são igualmente diversas formas de propriedade, isto é, o estágio existente da divisão do trabalho determina também as relações dos indivíduos uns com os outros em referência ao material, instrumento e produto do trabalho [...] A primeira forma de propriedade é a tribal [Stammeigentum]. Corresponde a um estágio pouco desenvolvido da produção em que as pessoas vivem da caça, pesca, criação de animais, e, no estágio mais avançado, agricultura [...] A divisão do trabalho neste estágio é muito elementar e confinada a uma extensão da divisão do trabalho existente na família. A estrutura social é, portanto, limitada a uma extensão da família: primeiro, os chefes patriarcais da tribo, abaixo os membros da tribo e, finalmente, os escravos [...] A segunda forma é a comunal ou estatal da Antiguidade, que provém especialmente da união de várias tribos em uma cidade por acordo ou conquista e que é ainda acompanhada do escravismo [...] A terceira forma é a feudal ou estamental [...] A mais importante divisão do trabalho mental e material é a separação da cidade do campo. A contradição entre cidade e campo começa na transição da barbárie para a civilização, da tribo para o Estado, do local para o nacional e flui por toda a história da civilização até hoje [...] A próxima extensão da divisão do trabalho foi a separação entre produção e comércio, a formação de uma classe especial de comerciantes [...] Com o intercâmbio investido em uma classe especial, com a extensão do comércio, através dos mercadores, para além dos arredores da própria cidade [...], as cidades entram em relações umas com as outras [...] A consequência imediata da divisão de trabalho entre as várias cidades é o aparecimento das manufaturas, ramos de produção que haviam crescido para além do sistema de guildas [...] O tipo de trabalho que desde o início pressupunha o uso de máquinas, mesmo da espécie mais 
rústica, logo se mostrou o mais capaz de desenvolvimento [...] A concentração do comércio e das manufaturas em um país, a Inglaterra, [...] criou para o país um relativo mercado mundial e, assim, uma demanda pelos produtos manufaturados daquele país que não podia ser satisfeita com as forças de produção da indústria até ali existente [...] A demanda, que cresceu mais que as forças produtivas, [...] foi o fator gerador da grande indústria [...], a forma mais expandida da divisão do trabalho [...] Esta "alienação" (para usar um termo que será entendido pelos filósofos) só pode, é claro, ser abolida a partir de duas premissas práticas. Ela tem que se tornar um poder "intolerável", isto é, um poder contra o qual os homens fazem revolução. Ela tem que ter deixado a grande massa da humanidade sem propriedade e, além disso, em contradição com um mundo de riqueza e cultura. Ambas as condições pressupõem um grande aumento das forças produtivas, um alto grau de seu desenvolvimento. E, por outro lado, esse desenvolvimento das forças produtivas (que implica na existência empírica real de homens com existência históricamundial em vez de local) é uma premissa prática absolutamente necessária porque, sem ela, haveria apenas uma generalização da carência e, com a pobreza, a luta pelas necessidades da vida e toda aquela sujeira antiga necessariamente se reproduziria. Além disso, tendo em vista que apenas com o desenvolvimento mundial das forças produtivas é estabelecido um intercâmbio mundial entre os homens, [...] empiricamente o comunismo só é possível como ato de todos os povos dominantes "de uma vez", simultaneamente (MEW, v. 3, p. 22-24, 31, 34-35, 50, 52-54, 59; negritos meus).

As passagens acima de A Ideologia Alemã dão algumas dicas suas e de Engels sobre o problema da divisão do trabalho e alienação. A busca pela origem da divisão do trabalho não chega a uma resposta concreta, mas aponta para algumas diferenças naturais que podem, dependendo das circunstâncias, serem a base para ela (a divisão entre homem e mulher, as estruturas da família). Mas, Marx, isso pode levar a conclusões fatalistas de que a origem da divisão do trabalho (e consequentemente da alienação) está na própria natureza. Para evitar esse dilema, seria necessário mostrar que esses fatores naturais (divisão 
entre os sexos, estruturas familiares) não dão origem "naturalmente" à divisão do trabalho e à alienação e sim que são necessários elementos outros (sociais) desencadeadores do processo nessa direção para que essas bases naturais levem à divisão do trabalho e alienação. Infelizmente, nessa obra, você e Engels não chegam a explorar o primum mobile social necessário para transfigurar esses elementos naturais em estruturas de alienação, quedando a dúvida se, então, alienação e divisão do trabalho teriam sido processos inevitáveis na história humana. Uma pena A Ideologia Alemã ter quedado inacabada (em geral e nesse ponto especificamente), pois imagino que, caso tivessem encontrado um editor para publicar a obra completa, você procuraria trabalhar para completar esta explicação de forma menos fatalista, quase como se fosse um fenômeno natural, e sim buscando os mecanismos sociais e históricos que fariam com que diferenças naturais que antes existiam sem gerar alienação ou divisão do trabalho generalizadas pudessem depois servir de base para tais processos alienantes. Estou certo?

Aliás, aproveito para tirar outra dúvida. Louis Althusser, em uma fase de sua carreira, partiu para uma explicação alternativa por que você não prosseguiu investigando essa e outras questões correlatas. Ele postulou o conceito do corte epistemológico na obra de Marx no período posterior à escrita das Teses Sobre Feurbach e A Ideologia Alemã em 184546. (Althusser, 1979, p. 25) Faria a distinção entre o jovem Marx da época anterior, mais preocupado com questões e conceitos filosóficos abstratos como essência humana, alienação etc. e o Marx maduro das épocas posteriores que crescentemente abandonaria tais veleidades filosóficas ("ideológicas") em busca de uma análise científica das questões sociais político-econômicas (epitomadas em $\mathrm{O}$ Capital). Seria por isso que não consegui prosseguir a trilha da busca da origem última da alienação que você deixou inconclusa em A Ideologia Alemã? Você simplesmente não estaria mais interessado em tais temas posteriormente? Concorda com essa tese do corte epistemológico de Althusser? Acredita que houve realmente uma ruptura radical entre seus trabalhos da juventude e os 
de sua idade mais avançada? Ou vê mais continuidades que rupturas em relação a elas? Nossos contemporâneos estão divididos sobre essa questão.

É da sua época posterior de maior envolvimento político, em redor da eclosão das revoluções de 1848 pela Europa, que vem minha segunda grande dúvida. Trata-se da famosa Mensagem do Comitê Central à Liga [dos Comunistas] de Março de 1850. Essa mensagem foi escrita depois da derrota das revoluções de 1848 pela Europa, numa época em que a Liga dos Comunistas, da qual você fazia parte, estava tentando se reconstruir após os golpes recebidos. Você, como membro destacado do Comitê Central da Liga, assinou o documento a ser enviado às diversas seções da organização. Ou seja, sancionou oficialmente as ideias do documento que, por um lado, retomava a noção de que era necessário talvez trabalho conspirativo para recobrar o ímpeto revolucionário e, por outro, lançava o slogan da revolução em permanência (que muita gente no século $X X$, especialmente os trotskistas, mas não apenas, leram como embrião para teorias de revolução permanente) $)^{2}$.

Uma grande parte dos membros [da Liga] que participaram do movimento revolucionário [de 1848] acreditou que a época das sociedades secretas tinha passado e que atividades abertas apenas eram suficientes. As comunidades e círculos individuais deixaram sua conexão com o Comitê Central se tornar solta e gradualmente dormente. Consequentemente, enquanto o partido democrático,

\footnotetext{
${ }^{2}$ Marx, apenas para seu conhecimento, a descrição clássica do conceito de revolução permanente em Trotsky se encontra em seu livro A Revolução Permanente. (Trotsky, 1985, p. 22-24) Curiosamente, o verbete Permanentnaya Revolyutsiya ["Revolução Permanente"] da Enciclopédia Histórica Soviética faz uma leitura análoga, mas oposta, do conceito na Mensagem à Liga: "A ideia da revolução permanente foi concebida primeiramente por Marx e Engels no [...] Manifesto Comunista e na Mensagem do Comitê Central à Liga dos Comunistas [... Lenin] desenvolveu-a na teoria da transformação da revolução democrático-burguesa em socialista [...] em 1905 [...] A teoria marxistaleninista da revolução permanente foi desvirtuada cruamente por Parvus e Trotsky, que criaram em 1905 a chamada teoria da 'revolução permanente', na base da qual estava a negação menchevique das possibilidades revolucionárias do campesinato" (SIS, v. 11, p. 43-44).
} 
o partido da pequena burguesia, se organizava cada vez mais na Alemanha, o partido dos trabalhadores perdia seu pé firme, se mantinha organizado nas diferentes localidades para propósitos locais e, dentro do movimento geral, caiu completamente sob dominação e liderança dos democratas pequeno-burgueses. Um fim precisa ser dado a este estado de coisas. A independência dos trabalhadores precisa ser restaurada [...] Enquanto os pequenoburgueses democráticos querem concluir a revolução o mais cedo possível [...], é interesse nosso, e nossa tarefa, tornar a revolução permanente até que todas as classes mais ou menos possuidoras tenham sido forçadas para fora de suas posições de poder, que o proletariado tenha conquistado o poder estatal, e que a associação dos proletários, não apenas em um país, mas em todos os países dominantes do mundo, tenha avançado tanto que a competição entre os proletários desses países tenha cessado e que pelo menos as forças produtivas decisivas estejam concentradas nas mãos dos proletários [...] Nosso grito de guerra deve ser: A Revolução em Permanência!"' (MEW, v. 7, p. 244, 247248 e 254)

Minha dúvida deriva do fato que o tom "ultraesquerdista" da Mensagem de 1850 (como um todo) não parece coadunar com as suas posições pessoais durante o desenrolar da revolução de 1848 na Alemanha especificamente. Quando você voltou à Alemanha para participar do processo em abril de 1848 e fundou, em maio, a Nova Gazeta Renana, logo se viu em disputa com a ala "obreirista" da Liga dos Comunistas, capitaneada por Andreas Gottschalk. Essa ala (à la Wilhelm Weitling) pregava uma atuação independente e mesmo algo exclusivista da classe trabalhadora, se recusando a alianças com outras classes e desconfiando dos intelectuais dentro do partido. Gottschalk, por exemplo, pregava um boicote às eleições para a Assembleia de Frankfurt. Você afirmava que a Alemanha, ainda presa a estruturais semifeudais, não tinha passado por uma revolução burguesa completa e, portanto, uma revolução, mesmo que ainda burguesa, na Alemanha, seria um progresso para os trabalhadores, que não deveriam se isolar sectariamente da luta democrática mais geral. Mantendo sua

20 Dúvidas de um biógrafo brasileiro de Marx 
independência, os trabalhadores deveriam impulsionar os avanços democráticos na autoritária Prússia de modo a criarem condições mais favoráveis para a sua futura luta própria pela revolução socialista. Pelo menos nos meses iniciais da revolução de 1848 na Alemanha, essa foi a sua posição. ${ }^{3} \mathrm{E}$, mesmo antes daquele ano, quando participou da reorganização da Liga dos Justos em Liga dos Comunistas em 1847, uma de suas críticas principais era às formas organizativas excessivamente conspirativas das sociedades secretas, que impediam uma maior divulgação do movimento entre a massa trabalhadora ${ }^{4}$. Como conciliar isso com a Mensagem à Liga de 1850 que dizia que a época das sociedades conspirativas ainda não tinha passado e pregava, nessa passagem acima e em outras, uma posição bastante intransigente em relação à burguesia? Estava você, Marx, fazendo, naquele documento coletivo, um compromisso com os membros mais "à sua esquerda" no Comitê Central da Liga dos Comunistas, como sugeriram Nicolaievsky \& Maenchen-Helfen (1973, p. 218-219, 224)? Ou realmente foi reflexo da visão modificada mais radical que você teve no período final de declínio das revoluções em 1849/1850, como defendeu McLellan (2006, p. 216)? Eu fiquei em dúvida nesse ponto, já que a falta de documentação primária mais detalhada sobre $o$ funcionamento da Liga nos impossibilita, no momento atual, de chegar a uma conclusão peremptória.

\footnotetext{
${ }^{3}$ Ver, por exemplo, seu discurso de 04/08/1848 na Associação Democrática de Colônia contra Weitling, as minutas da reunião da Liga dos Comunistas de 11/05/1848 (quando Gottschalk se retirou dela), sua discussão original com Weitling em Bruxelas em 30/03/1846 e sua discussão contra August Willich na reunião da Liga dos Comunistas de 15/09/1850, respectivamente em MECW, v. 7, p. 556-557; MEW, v. 5, p. 484; Annenkov, 1883, p. 237-239; e MEW, v. 8, p. 598-600.

${ }^{4}$ Engels deixou bem claro essa posição de vocês de tentarem sair dos limites de meras sociedades conspirativas quando da reorganização da Liga dos Justos em Liga dos Comunistas em seu texto Sobre a História da Liga dos Comunistas: "A experiência de 12 de maio os tinha ensinado que naquele momento nada havia a se ganhar com tentativas de putsch [e] se as velhas regras semiconspirativas ainda foram preservadas intactas, isso era culpa da antiga rebeldia revolucionária que começava a colidir com visões mais esclarecidas" (MEW, v. 26, p. 316-317).
}

cadernos cemarx, $\mathrm{n}^{\mathrm{o}} 11-2018$ 
Finalmente, um último ponto a ser esclarecido tem a ver com a Rússia, país ao qual o seu nome é frequentemente ligado devido à experiência soviética. Sintomaticamente, o bicentenário do seu nascimento em 2018 veio logo depois do centenário da Revolução Russa em 2017: uma compressão temporal desta ligação de Marx com a Rússia! Se atualmente esta proximidade ficou quase contígua, em sua época a possibilidade desta aproximação absolutamente não era clara e poderia até ser considerada improvável. Em um artigo anterior meu, intitulado Karl Marx e a Revolução Russa, resumi assim a evolução de sua posição em relação àquele país eslavo:

A atitude de Marx em torno da possibilidade [de a revolução socialista ocorrer na Rússia] se modificou ao longo da vida e está muito imbricada com a maneira como o Mouro via a Rússia de maneira geral. Grosso modo, podemos distinguir duas grandes fases gerais com um longo período de transição entre elas. $\mathrm{Na}$ parte inicial de sua carreira intelectual, Marx tendia a ver a Rússia como o bastião da reação, o país que poderia impedir a revolução progressista na Europa: seu grande modelo histórico foi o papel da Rússia na derrota de Napoleão, encurralando os ideais revolucionários franceses de 1789/1793. Com a derrota das revoluções de 1848 e da Comuna de Paris de 1871 na Europa Ocidental, nos anos finais de sua vida, o Mouro passa a dedicar uma atenção cada vez mais forte ao potencial revolucionário dos desenvolvimentos na Rússia. O período de transição entre as duas fases se refere ao fato de que o envolvimento de Marx com os próprios revolucionários russos para um aprofundamento de seus conhecimentos do país já se inicia antes. Marx publicara o volume I de O Capital em 1867 e, ironicamente, a primeira tradução em língua estrangeira se daria na... Rússia! A tradução russa seria publicada em 1872, mas desde 1868 o tradutor, Nikolai Danielson, se engaja em forte correspondência com Marx na qual ele não apenas tira dúvidas da tradução, mas também envia a Marx grandes volumes de estatísticas sobre a Rússia que servirão para que o Mouro possa aprofundar seus próprios estudos sobre aquele país eslavo. Marx inclusive aprenderia russo para poder trabalhar essas fontes primárias na língua original. A ironia desse momento de transição, quando o Mouro passaria a escrever 
sobre a Rússia não mais "de fora" (com fontes secundárias ocidentais) e sim "de dentro" (a partir de fontes primárias russas na língua original), se deu também pelo fato de que o contato de maior relevo inicial de Marx com os revolucionários russos se passou mais com os narodniki ("populistas") que com os próprios marxistas russos de então (que inclusive eram adversários da ideologia narodnik). Além disso, dentro dessa fase "de transição", devemos notar o ponto de viragem do período de repensar na Rússia após a Guerra da Crimeia (1853-1856) que desaguaria na abolição da servidão no país em 1861, a partir do qual Marx começa a aventar a possibilidade da Rússia ter potencial revolucionário pelo menos dentro do quadro de uma revolução europeia ou mundial mais ampla (Segrillo, 2017, p. 481-482).

Desculpando-me por tê-lo tratado na passagem acima pelo seu apelido informal ("Mouro"), minha principal dúvida sobre sua relação com a Rússia se refere ao período final mencionado, quando você (já conhecendo bem melhor o país a partir das próprias fontes primárias em russo) começa a aventar a possibilidade de uma revolução lá ocorrer. Alguns autores (e.g., Little, 2010; Heinrich, 2016, p. 130131), examinando seus últimos manuscritos não publicados em vida (por exemplo, os chamados Cadernos Etnológicos ou os rascunhos da carta à Vera Zasulitch de 08/03/1881) e sua correspondência com os populistas russos, dizem que você, nessa fase final, estava a ponto de fazer uma grande viragem em seu pensamento, passando de uma visão evolucionista centrada na Europa ocidental para a aceitação da possibilidade de outras vias de chegada ao socialismo, incluindo a de que a assim chamada comuna rural russa (mir) pudesse servir de base para um futuro desenvolvimento do socialismo no país (Marx, 1974; Sochineniya, v. 19, p. 400-421). Pessoalmente, acho que essa visão é algo exagerada. Por isso queria saber com você ao certo.

O caso da carta datada de 16/02/1881 da (então populista e depois marxista) Vera Zasulitch a você está no cerne desta questão. Zasulitch lhe perguntara "à queima-roupa" se a comuna rural russa poderia servir como ponto de partida para a implantação do socialismo 
na Rússia, como queriam os populistas narodniki e como negavam os próprios marxistas russos. O filósofo Daniel E. Little, da Universidade de Michigan, citou, entre outras, a seguinte parte dos rascunhos que você preparou para a réplica à Zasulitch, a fim de demonstrar que sua resposta seria afirmativa:

Do ponto de vista histórico, o único argumento sério em favor da dissolução fatal da comuna rural russa é o seguinte: Se formos muito atrás no tempo, a propriedade comunal de um tipo mais ou menos arcaico pode ser encontrada por toda a Europa ocidental: em toda parte ela desapareceu com o progresso social. Por que somente na Rússia ela escaparia desse destino? Eu respondo: porque na Rússia, devido a uma combinação única de circunstâncias, a comuna rural, ainda estabelecida em escala nacional, pode gradualmente se destacar de suas características primitivas e se desenvolver diretamente como elemento de uma produção coletiva em escala nacional. É precisamente devido à sua contemporaneidade com a produção capitalista que ela pode se apropriar das aquisições positivas desta última sem experimentar todos seus terríveis infortúnios. A Rússia não está isolada do mundo moderno e não é vítima de um invasor estrangeiro como a Índia (Little, 2010).

O trecho acima (e outros citados pelo prof. Little) parece fornecer uma resposta positiva (e até otimista) sua, Marx, à possibilidade de a comuna rural ser a base para um desenvolvimento socialista alternativo na Rússia. Entretanto, em meu artigo, eu chamo a atenção que esses trechos são do rascunho da carta que você escreveria em resposta à missiva de Zasulitch. A carta propriamente dita que você enviou à Zasulitch, era muito mais contida e lacônica que os longuíssimos rascunhos que escreveu para ela. Como ela é relativamente curta, vale a pena reproduzi-la in toto:

8 de março de 1881. 41, Maitland Park Road, Londres N.W. Cara Cidadã: Um problema de nervos que tem me afetado periodicamente nos últimos dez anos me impediu de responder antes sua carta de 16 de fevereiro. Eu lamento que não possa 
lhe dar um texto para publicação sobre a questão que me deu a honra de levantar. Alguns meses atrás, eu prometi um texto sobre o mesmo assunto ao Comitê de São Petersburgo. Mesmo assim, espero que algumas linhas sejam suficientes para tirá-la da dúvida sobre a maneira como a minha chamada teoria foi mal entendida. Analisando a gênese da produção capitalista, eu disse: “No cerne do sistema capitalista está a separação do... produtor dos meios de produção... a expropriação do produtor rural é a base de todo o processo. Somente na Inglaterra ele foi completado de maneira radical... Mas todos os outros países da Europa Ocidental estão seguindo o mesmo curso." (Capital, edição francesa, p. 315) Portanto, a "inevitabilidade histórica" de tal curso é expressamente restrita aos países da Europa Ocidental. A razão para essa restrição é indicada no cap. XXXII: "A propriedade privada baseada no trabalho pessoal... é suplantada pela propriedade privada capitalista, que se baseia na exploração do trabalho de outros, no trabalho assalariado." (loc. cit., p. 340) No caso ocidental, então, uma forma de propriedade privada é transformada em outra forma de propriedade privada. No caso dos camponeses russos, entretanto, sua propriedade comunal teria que ser transformada em propriedade privada. Então, a análise em $O$ Capital não dá argumentos pró ou contra a vitalidade da comuna russa. Mas o estudo especial que fiz dela, incluindo pesquisa em material de fontes originais, me convenceu que a comuna é o fulcro para a regeneração social na Rússia. Mas, a fim que possa preencher essa função, as influências nocivas que a cercam de todos os lados precisam ser eliminadas antes para que ela possa ter asseguradas as condições normais de desenvolvimento espontâneo. Cara cidadã, tenho a honra de permanecer. Sinceramente Seu, Karl Marx. (MEW, v. 19, p. 242-243)

Ou seja, você, Marx, que chegou perto de dar uma resposta positiva à pergunta de Zasulitch nos diversos rascunhos que escreveu para sua missiva, pensou melhor e resolveu dar uma resposta bem mais contida. Por ela a comuna rural pode fazer esse papel, mas apenas dadas certas condições ${ }^{5}$.

${ }^{5}$ Essa diferença entre "rascunho" e "carta real" no caso da correspondência com 
Essa sua resposta final à Zasulitch parece coadunar com o último escrito público que você, conjuntamente com Engels, redigiu sobre o assunto. Foi no prefácio que vocês dois escreveram à segunda edição russa (de 1882) do Manifesto Comunista:

O Manifesto Comunista tinha como objeto a proclamação da iminente dissolução inevitável da propriedade burguesa moderna. Mas na Rússia nós descobrimos, ao lado do capitalismo e da propriedade agrária burguesa que estão somente agora rapidamente se desenvolvendo, mais de metade da terra em pertença comunal pelos camponeses. Então a questão é: a comuna rural russa, mesmo sendo uma forma muito minada da antiga propriedade comum da terra, pode passar diretamente à forma superior comunista de propriedade comum? Ou, ao contrário, precisa antes passar pelo mesmo processo de dissolução que constituiu a evolução histórica do Ocidente? A única resposta possível hoje é a seguinte: se a revolução russa se tornar um sinal para a revolução proletária no Ocidente, de modo que as duas se complementem, então a presente propriedade comum da terra na Rússia pode servir de ponto de partida para um desenvolvimento comunista (MEW, v. 19, p. 296; cf. Sochineniya, v. 19, p. 305).

Ou seja, "Se..., pode..." parece ser sua fórmula, muito no condicional, para resolver esta questão espinhosa. Parece-me, então, que, no seu período final, em que estudava a Rússia através de

Zasulitch chama a atenção para um problema metodológico importante hoje quando, devido ao admirável trabalho feito pelos editores da MEGA (Marx-EngelsGesamtausgabe), a mais completa coleção de textos e documentos seus e de Engels, incluindo seus rascunhos e manuscritos não publicados, os pesquisadores estão empregando também seus rascunhos em suas descrições do pensamento marxiano. A utilização de rascunhos (de qualquer autor, não apenas seus, Marx) deve ser feita com extrema cautela, evitando tirar daí conclusões precipitadas. Afinal, rascunhos são usados como a fase experimental de uma pesquisa (onde, ao lado de acertos, muitos erros são feitos e corrigidos, no caso, riscados ou eliminados do texto final). Assim, como alguém que sai para a rua quer ser visto em suas melhores roupas de sair, bem arrumadinho (e não que o vejam de pijama ou roupas de baixo como costuma andar em casa), as ideias de um autor, ceteris paribus, devem ser julgadas a partir de seu texto final e não de seus rascunhos. Procede? 
fontes primárias e em correspondência com muitos autores russos influenciados pelo populismo, você, Marx, realmente se abriu (bem mais que no início de sua carreira!) para possibilidades revolucionárias na Rússia, algumas das quais hipoteticamente a partir da própria comuna rural. Mas seria um exagero qualificar esta mudança de atitude como um rompimento radical com suas posições anteriores ou que você estivesse prestes a assumir uma posição próxima ao populismo russo. Em minha visão, você simplesmente tinha notado que a Rússia (após a abolição da servidão em 1861) estava em uma nova fase, agora de desenvolvimento capitalista e possibilidade de uma real revolução burguesa (talvez de um tipo peculiar) e isso exigia que você visse o país com olhos diferentes daqueles com os quais o via antes da abolição da servidão.

Estou certo nesse ponto?

Finalmente, a curiosidade maior de todas, é claro, seria lhe perguntar o que você acha dos desenvolvimentos do socialismo no século $X X$, em especial, como viu o regime soviético e a maioria dos movimentos marxistas atuais. Mas não vou fazer essa pergunta, porque, na verdade, a sua opinião não importa. Você nunca se colocou em termos religiosos, como um ser onisciente e infalível. Você falou do que conhecia bem: a realidade do seu tempo e, dialeticamente, sempre anunciou que ela era dinâmica e necessitava de estudo constante para manter a estratégia e táticas mais adequadas para os diferentes momentos. Assim, como estamos mesmo sem você, e nós, marxistas, em consequência, temos que pensar com nossas próprias cabeças para o desenvolvimento adequado do marxismo no momento atual, nem vou fazer essa pergunta para não acalentar esperanças vãs de que se alguém soubesse o que Marx realmente pensava, isso seria suficiente para resolver os dilemas do socialismo hoje.

Respeitosamente,

Angelo Segrillo 


\section{Referências bibliográficas}

ALTHUSSER, Louis. A Favor de Marx. 2ª ed. Rio de Janeiro: Zahar, 1979.

ANNENKOV, Pavel. Eine Russische Stimme über Karl Marx. Die Neue Zeit, v. 1, n. 5, p. 236-241, 1883.

HEINRICH, Michael. "Capital" after Mega: Discontinuities, Interruptions and New Beginnings. Crisis and Critique, v. 3, n. 3, p. 92-138, 2016.

K. Marks, F. Engels Sochineniya. $2^{\mathrm{a}}$ ed. Moscou: Izdatel'stvo Politicheskoi Literatury, 1955-1974. 50 vols.

Karl Marx Friedrich Engels Werke. Berlim: Dietz Verlag, 1956-1977. 43 vols.

LITTLE, Daniel. Marx on Russia. Understanding Russia, 14/04/2010. Disponível em: <https://understandingsociety.blogspot.com. br/2010/04/marx-on-russia.html>

MARX, Karl. The Ethnological Notebooks. $2^{\underline{a}}$ ed. Assen (Holanda): Van Gorcum \& Comp. B.V., 1974.

Marx-Engels Collected Works. Londres: Lawrence \& Wishart, 1975-2004. 50 vols.

McLELLAN, David. Karl Marx: a Biography. 4⿳亠丷. ed. Nova Iorque: Palgrave Macmillan, 2006.

MECW: ver Marx-Engels Collected Works.

28 Dúvidas de um biógrafo brasileiro de Marx 
MEW: ver Karl Marx Friedrich Engels Werke.

NICOLAIEVSKY, Boris \& MAENCHEN-HELFEN, Otto. Karl Marx: Man and Fighter. Londres: The Penguin Press, 1973.

SEGRILLO, Angelo. Karl Marx e a Revolução Russa. Estudos Históricos, v. 30, n. 61, p. 479-496, maio-agosto 2017.

. Karl Marx: uma biografia dialética. Curitiba: Prismas, 2018.

Sochineniya: ver K. Marks, F. Engels Sochineniya.

Sovetskaya Istoricheskaya Entsiklopediya. Moscou: Izdatel'stvo "Sovetskaya Entsiklopediya", 1961-1976. 16 vols.

TROTSKY, Leon. A Revolução Permanente. 2ª̣ ed. São Paulo: Kairós, 1985. 
